\title{
First demonstration and field trial on multi-user UDWDM-PON full duplex PSK-PSK with single monolithic integrated dual-output-DFB-SOA based ONUs
}

\author{
GuangYong Chu ${ }^{1}$, Anaëlle Maho ${ }^{2}$, Iván Cano ${ }^{1}$, Victor Polo ${ }^{1}$, Romain Brenot ${ }^{2}$, Hélène \\ DEBrÉGEAS ${ }^{2, *}$, AND JOSEP PRAT ${ }^{1}$ \\ ${ }^{1}$ Dept. Signal Theory and Communications, Universitat Politècnica de Catalunya (UPC), Jordi Girona 31, 08034, Barcelona, Spain \\ ${ }^{2}$ III-V lab, Avenue Augustin Fresnel 1, 91767 Palaiseau, France \\ *Corresponding author: Helene.Debregeas@3-5lab.fr
}

Compiled July 20, 2016, revised September 9, 2016.

We demonstrate a monolithically integrated dual-output DFB-SOA, and conduct the field trial on multi-user bidirectional coherent UDWDM-PON. First time achievement on simplified single integrated laser based neighboring coherent ONUs with $12.5 \mathrm{GHz}$ channel spaced ultra-dense access network including both DS and US, taking the benefits of low footprint, low-temperature-dependence. $\odot 2016$ Optical Society of America

OCIS codes: (060.4250) Network; (060.1660) Coherent communications; (130.3120) Integrated optics devices; (060.2330) Fiber optics communications

http://dx.doi.org/10.1364/ol.XX.XXXXXX

For implementing the near future 5G infrastructure public private partnership (5G-PPP), todays optical access network (OAN), mobile back- and front-hauling, as well as data center connecting are required to be refreshed [1,2]. Optical coherent transmission systems are hopefully expected to be introduced soon also in access networks for real deployment, namely coherent ultra-dense wavelength division multiplexing-passive optical network (UDWDM-PON) [2-4]. However, the footprint, the cost and complexity of the optical network unit (ONU) are the main challenges [5].

Photonic integration on both Silicon and $\operatorname{InP}$ are ways for lower footprint ONU [6, 7], and the single integrated laser which has dual output optical paths, provides the possibility of simplified ONU recently [8-10].

Here we demonstrate, for the first time, a novel structure distributed feedback laser with semiconductor optical amplifier (DFB-SOA) as dual-output integrated chip for the coherent $\mathrm{ONU}$ of a multi-user $2.5 \mathrm{~Gb} / \mathrm{s} /$ user full duplex field trial UDWDM-PON. It provides a strong evidence for supporting a new effective and simplified structure of the integrated UDWDM-PON ONU.
The integrated DFB-SOA, consisting of DFB section $(250 \mu \mathrm{m}$ long) and SOA section (500 $\mu \mathrm{m}$ long), is designed and fabricated for single laser based UDWDM-PON ONU. The active layer is grown by metal-organic chemical vapor deposition (MOCVD) on InP substrates [11]. The active region contains compressively strained quantum wells (QWs) and tensile strained barrier layers [11]; both are made in AlGaInAs. The QW stack is about 200 $\mathrm{nm}$ sandwiched by two separate confinement heterostructures (SCHs). The ridge waveguide is buried by p-doped InP. In the DFB, the periodic change of the refractive index is provided traditionally by a special grating layer above the active layer (real index coupling). In our device, we chose a complex coupling by etching directly the active layer. By this way, we integrate a DFB to the SOA without changing the process fabrication. This kind of design simplifies the process fabrication and thus the cost of the component.

The same active layer is used for both the DFB and the SOA, emitting at $1544 \mathrm{~nm}$ for operating at C-band. It provides two outputs: one for the DFB and another for the SOA. The operation principle can be understood from the cross sectional schematic as shown in Figure 1(a); both facets are anti-reflection (AR, $R: \sim 0.01 \%$ ) coated after spot size converter (SSC) in order to provide high output power. The DFB-SOA chip (linewidth, $\Delta v \approx 10 \mathrm{MHz})$ assembled on a sub-mount [11-13] $\overline{(\text { size } 2 \mathrm{~mm}}$ $\times 6 \mathrm{~mm} \times 0.5 \mathrm{~mm}$ ) with its radio frequency $(\mathrm{RF})$ data accesses ceramics for the DFB and the SOA.

In Figure 1(b), two tapered single mode fiber (SMF) can be noticed at both sides, one for the SOA and another for the DFB. A temperature sensor $\left(R_{N T C}\right)$ is placed beside of the sub-mount, and kept around $25^{\circ} \mathrm{C}$. Unlike the previous work on dual-driven electro-absorption modulation laser (DEML) [9]; when the DFB-SOA chip is operated with $I_{D F B}=70 m A, I_{S O A}=100 m A$ at $25^{\circ} \mathrm{C}$, the SOA output provides $10 \mathrm{dBm}$ output power for uplink, and the DFB output provides $-2 \mathrm{dBm}$ which is much higher than the previous -9 dBm [9].

In order to modulate the SOA, a resistor of $47 \Omega$ is placed for effective matched impedance [14,15]. With the purpose of mod- 
ulating the SOA in phase, a specific characterization is carried out [16]. As shown in Figure 1(c), the 3-dB modulating bandwidth (BW) is around $2.2 \mathrm{GHz}$, and the phase modulating efficiency (PME) is also derived around 10 degree $/ \mathrm{mA}$ at $2.5 \mathrm{GHz}$.

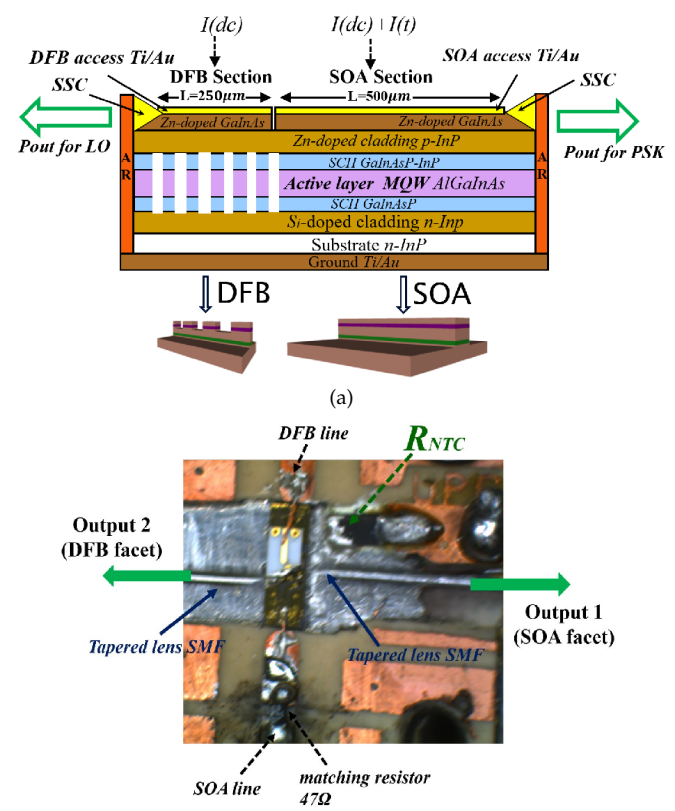

(b)

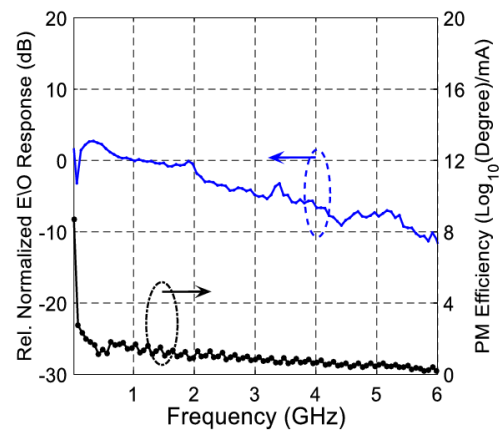

(c)

Fig. 1. (a) Cross-sectional schematic of the dual side DFB-SOA (Pout: output power, LO: local oscillator laser); (b) assembled 2-output-DFB-SOA; (c) AM response and PME of the SOA.

The experimental setup depicted in Figure 2(a) is assembled to study the multi user coherent UDWDM-PON employing phase-shift keying (PSK) modulation. For the setup, the optical line terminal (OLT) consists of two UDWDM transceivers (TRx) coupled, each TRx transmitting to one ONU. The two TRx at the OLT are coupled before transmitting over the optical distribution network (ODN), consisting of $10 \mathrm{~km}$ field deployed fiber with $\sim 10 \mathrm{~dB}$ loss, crossing Pisa city in Italy as shown in Figure 2(b) and $10 \mathrm{~km}$ SMF with approximately $2 \mathrm{~dB}$ loss in the lab. A variable optical attenuator (VOA) is set at the ODN as well. Then a coupler distributes two TRx for two ONUs (as shown in Figure 2(c)), including a non-integrated DFB-RSOA based single laser ONU which is described in [10] and the integrated DFB-SOA ONU.

In order to analyze the performance of the $u_{\text {ser }}\left(\mathrm{TR}_{1}\right.$ at the OLT and $O N U_{1}$ ), we first test the unidirectional transmission for both downstream (DS) and upstream (US); then, bidirec- tional transmission; finally both users are active and tested bidirectionally. The channel spacing between two users is as narrow as $12.5 \mathrm{GHz}$, a submultiple of the standard DWDM spacing, but here including both DS and US. The optical spectrum of both users modulated at $2.5 \mathrm{~Gb} / \mathrm{s}$ is shown in Figure 2(d). Due to the loss, at the OLT, a 50/50 coupler replaces the arrayed waveguide grating (AWG) which was set in the COCONUT demonstration setup [17], and the $\overline{1: 4}$ power splitter splits the optical signal to the ONUs [18].

At the OLT, the external cavity laser (ECL) output is divided with an optical coupler $(90 / 10)$, reused as the LO for the Rx. For the DS, a $2.5 \mathrm{~Gb} / \mathrm{s}$ non-return-to-zero (NRZ) data generated with a pulse pattern generator (PPG) modulates a $\mathrm{LiNbO}_{3}$ phase modulator (PM), with low insertion losses of $2.2 \mathrm{~dB}$. The DS optical signal is then sent through the ODN. At the ONU, the DFB section of the integrated DFB-SOA is employed as the $\mathrm{LO}$, tuned at $5 \mathrm{GHz}$ shifted against the DS carrier, which provides an intermediate frequency (IF) to perform the heterodyne detection. The DS and LO are mixed in a $3 \mathrm{~dB}$ coupler and one output is detected with 1 photodiode (PD) followed by a low-noise electrical amplifier. The electrical signal is band-pass filtered, decoded with a delay and multiply block and low-pass filtered [9]. The bit error ratio (BER) is then measured. The US uses the same DFB in the integrated DFB-SOA at the ONU as optical carrier. The SOA section $\left(I_{D F B}=70 \mathrm{~mA}, I_{S O A}=100 \mathrm{~mA}\right)$ of the DFB-SOA is modulated with $2.5 \mathrm{~Gb} / \mathrm{s}$ NRZ pseudo random binary sequence (PRBS) data to generate a PSK signal $\left(I_{p p}=20 m A_{p p}\right)$. After the distribution network, at the OLT the US signal is coherently detected with a heterodyne Rx with the ECL optical output as LO. As in the ONU, only 1 PD is used for detection. Afterwards, the electrical signal is amplified and band-pass filtered before computing the BER.

The BER against the received input power is shown in Figure 3(a) and Figure 3(b) for DS and US, respectively. For the unidirectional DS, the signal generated from the DFB provided $-2 \mathrm{dBm}$ at the receiver side for $\mathrm{LO}$, which improved greatly compared with the traditional backfacet (only $-9 \mathrm{dBm}$ [9]). The sensitivity at $B E R=10^{-3}$ reaches $-38.2 \mathrm{dBm}$, and $-36.4 \mathrm{dBm}$ for $\mathrm{BtB}$ and Pisa city fiber, respectively; unlike the traditional lab measurement described in [9], higher penalty is found here with field trial fiber. Besides, the $2.5 \mathrm{~Gb} / \mathrm{s}$ signal spectrum from electrical spectrum analyser (ESA) is shown in the inset of Figure 3(a). In the US direction, the signal is modulated in the SOA section, and reaches $-40 \mathrm{dBm}$ and $-37.5 \mathrm{dBm}$ for $B E R=10^{-3}$ at the OLT for BtB and field fiber, respectively. The US LO provides 0 $\mathrm{dBm}$, which maintains the same standard value as described in [9], explaining the reason why the US performances improves the sensitivity compared to the DS. The eye diagram and the signal spectrum are also shown in the inset of Figure 3(b).

After the proper detection of DS and US separately, $\mathrm{TR}_{1}$ and $\mathrm{ONU}_{1}$ are put into operation simultaneously with the $5 \mathrm{GHz}$ spectral separation. The BER results are plotted in Figure 4(a). For the DS direction, at $B E R=10^{-3}$, the DS Rx sensitivity is -37 $\mathrm{dBm}$ in $\mathrm{BtB}$, which is $1.2 \mathrm{~dB}$ larger than the unidirectional DS, mainly due to some reflections caused by optical components appearing in the bidirectional system. When applying the field trial link, the sensitivity reaches $-33.5 \mathrm{dBm}$ (Figure 4(a)); there is $3.1 \mathrm{~dB}$ penalty compared with unidirectional DS (Figure 3(a)); this is attributed to the back scattering and reflections effects when implemented in bidirectional system [19]. The same reason well explains that the penalty between $\mathrm{BtB}$ and field trial fiber here is approximately $3.5 \mathrm{~dB}(1.7 \mathrm{~dB}$ larger than unidirectional DS). 


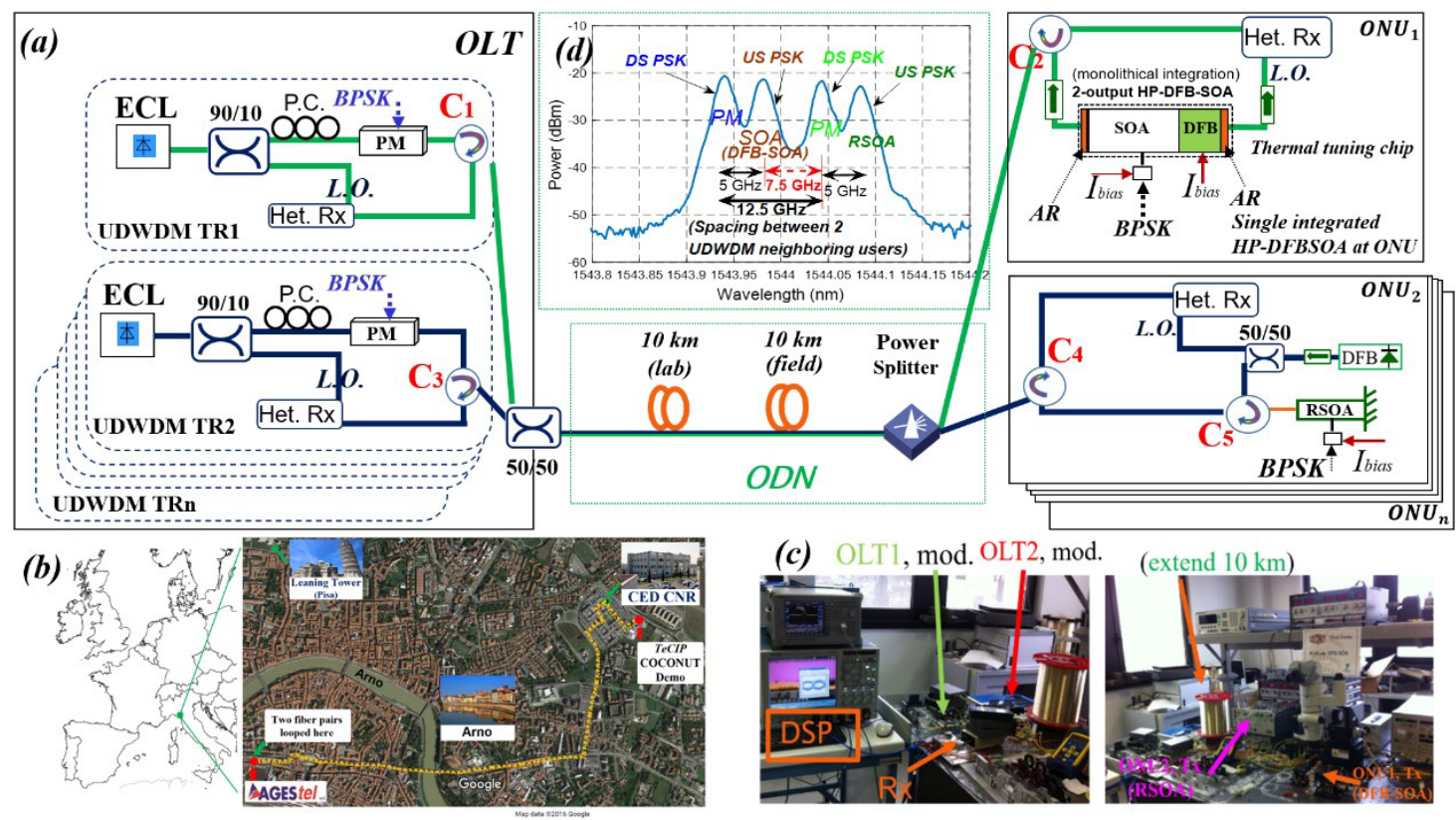

Fig. 2. (a) Field-trial setup for multi user UDWDM-PONs; (b) Satellite view of the field trial fiber links from TeCIP to AGEStel; (c) Laboratory infrastructure; (d) Optical spectra.

For the bidirectional US, like DS, there is spectral overlap between DS and US [20], hence it slightly influences the BER performances; the sensitivity reaches $-38.4 \mathrm{dBm}$ and $-35.2 \mathrm{dBm}$ for BtB and field trial, respectively; a $3.2 \mathrm{~dB}$ penalty yielded. Both US and DS are successfully detected.

A total power budget of $41 \mathrm{~dB}$ for ODN loss is provided for bidirectional system at $2.5 \mathrm{~Gb} / \mathrm{s}$. This is more than enough to support long reach operations [21] (up to $100 \mathrm{~km}$ length in theory, corresponding nominally to $20 \mathrm{~dB}$ losses) and more than $28 \mathrm{~dB}$ [22] margin to allow for power splitting and other intrinsic ODN losses. After completing the single user bidirectional transmission, a neighboring user is added for multi user operation with $12.5 \mathrm{GHz}$ spacing. The added user $_{2}$ uses the same RSOA described in [10]. Similarly to user $_{1}$, the DS modulator of user $_{2}$ at the OLT side uses a similar $\mathrm{LiNbO}_{3} \mathrm{PM}$.

The bidirectional transmission performances are presented here in this multi-UDWDM-neighboring user condition, the spectrum, including DS and US for user $_{1}$ and user $_{2}$, is obtained as shown in Figure 2(d). The results are plotted in Figure 4(b). The DS using DFB-SOA as LO, the sensitivities are $-35.7 \mathrm{dBm}$ and $-32 \mathrm{dBm}$ for $\mathrm{BtB}$ and field trial; compared to the bidirectional DS in Figure 4(a), a $1.3 \mathrm{~dB}$ penalty is obtained in multi user $\mathrm{BtB}$ condition, and this is mainly due to the received signal including the two users signal from the OLT, however the $\mathrm{Rx}$ detects only one of these data carried by optical waveforms. This behavior is also presented in field trial condition, showing $1.5 \mathrm{~dB}$ penalty.

The US modulates the SOA in the same condition as previously, and the sensitivities are $-37 \mathrm{dBm}$ and $-33.4 \mathrm{dBm}$ for $\mathrm{BtB}$ and field trial, respectively. As explained in the DS, similarly, at the OLT the Rx receives the signal from both ONUs, but detecting only one of them taking the benefit of the wavelength selectivity by heterodyne Rx. We can see the sensitivity penalty attributed to the interference between users, however less than $2 \mathrm{~dB}$ only. Both users transmit and receive data successfully. During the experiment, no visible interference or signal degradation has been observed between the UDWDM neighboring ONUs, thus providing a strong effective evidence on the deployed UDWDM scenario. The performance of bidirectional UDWDM transmission on this single laser based $\overline{\mathrm{ONU}}$ is mainly interfered by neighboring users, from the field trial tests on $u_{\text {ser }}$ performance, the neighboring user $_{2}$ has not influenced on user $_{1}$ 's performance seriously. Based on this, it is supposed that, the near future network could support and transmit at $2.5 \mathrm{~Gb} / \mathrm{s} /$ user when neighboring users are applied with this $12.5 \mathrm{GHz}$ spacing [23].

A monolithically integrated anti-reflective DFB-SOA has been demonstrated for the first time, and we can thus conclude that a field trial with multi-user bidirectional transmission for coherent ultra-dense access network, providing a way of mass deployment for real UDWDM-PON system with simplified structure. The dual output DFB-SOA serves as both Tx and LO. Two neighboring users are both tested at $2.5 \mathrm{~Gb} / \mathrm{s} /$ user PSKPSK bi-directionally, enabling a channel spacing at $12.5 \mathrm{GHz}$ between users. Extremely simplified structure for both Tx and $\mathrm{Rx}$, consisting of single PD and single integrated laser chip, is used at ONU and achieves high sensitivity cost effectively.

\section{FUNDING}

Spanish Ministry of Science and Innovation FLIPER (TEC201570835); European FP7 COCONUT (GA318515).

\section{ACKNOWLEDGE}

The authors thank Dr. W. Zhou from Tohoku Univ. and C. Kazmierski from III-V lab for fruitful discussions, Dr. M. Presi, Dr. M. Artiglia and Dr. E. Ciaramella from TeCIP, Italy for the Pisa city fiber distribution and fruitful discussions, J. Giner and R. T. López from MWERF Lab of UPC for circuit fabrication, F. Bottoni from TeCIP Institute for the ECLs supply. The satellite map is authorized by Google Inc. 


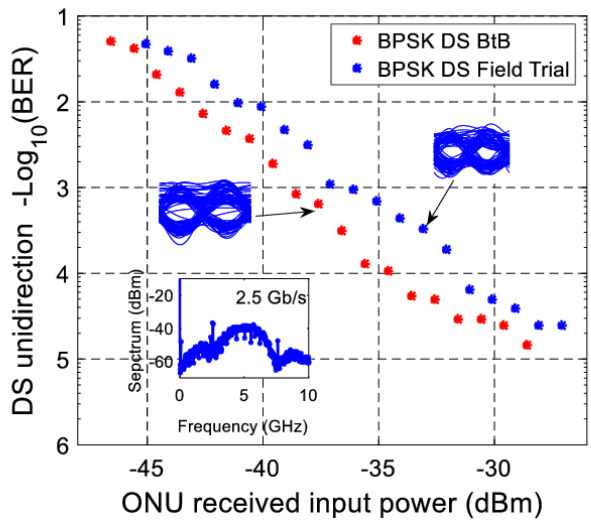

(a)

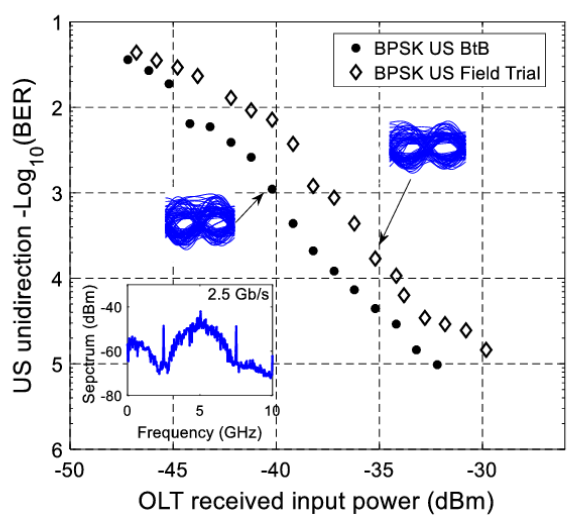

(b)

Fig. 3. (a) DS BER versus received power (The insets. heterodyne spectrum from ESA and eye diagram); (b) US BER versus received power (The insets. heterodyne spectrum from ESA and eye diagram).

\section{REFERENCES}

1. P. Ghelfi, F. Laghezza, F. Scotti, G. Serafino, A. Capria, S. Pinna, D. Onori, C. Porzi, M. Scaffardi, A. Malacarne, V. Vercesi, E. Lazzeri, F. Berizzi, and A. Bogoni, Nature, 507, 341-345, (2014).

2. J. G. Andrews, S. Buzzi, W. Choi, S. V. Hanly, A. Lozano, A. C. K. Soong, and J. C. Zhang, IEEE Journal on Selected Areas in Communications 32, 1065 (2014).

3. S. Smolorz, H. Rohde, E. Gottwald, D. W. Smith, and A. Poustie, in Optical Fiber Communication Conference, 2011, p. PDPD4.

4. M. Presi, M. Artiglia, and E. Ciaramella, Optics letters 39, 6301 (2014).

5. S. A. Gebrewold, L. Marazzi, P. Parolari, R. Brenot, S. P. Duill, R. Bonjour, D. Hillerkuss, C. Hafner, and J. Leuthold, IEEE Journal of Selected Topics in Quantum Electronics,20, 503 (2014).

6. D. Ding, L. Pereira, J. Bauters, M. Heck, G. Welker, A. Vantomme, J. Bowers, D. MJA, and D. Bouwmeester, Nature Photonics, pp. 1-6 (2016).

7. C. Kazmierski, D. Carrara, K. Lawniczuk, G. Aubin, J.-G. Provost, and R. Guillamet, in Optical Fiber Communication Conference, 2013, pp. OW4J8.

8. J. Prat, in Optical Fiber Communication Conference, 2015, pp. Th3I-3.

9. G. Y. Chu, I. Cano, V. Polo, C. Kazmierski, R. Brenot, and J. Prat, Journal of Lightwave technology, 34, 8 (2016).

10. G. Y. Chu, V. Polo, A. Lerín, J. Tabares, I. N. Cano, and J. Prat, Optics Communications 357, 34 (2015).

11. A. Maho, G. Simon, S. Barbet, F. Lelarge, F. Saliou, P. Chanclou, P. Parolari, L. Marazzi, M. Brunero, M. Martinelli, R. Brenot, Journal of Lightwave technology, 34, 2 (2016).

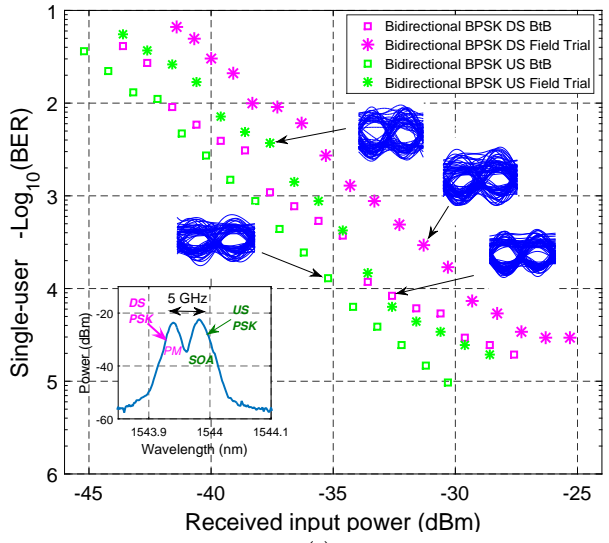

(a)

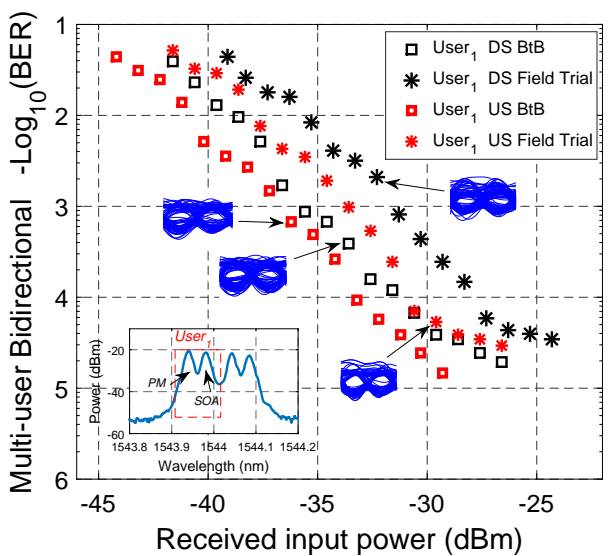

(b)

Fig. 4. (a) single user bidirectional transmission; (b) full duplex BER performances in multi UDWDM user transmission condition.

12. G. De Valicourt, D. Make, J. Landreau, M. Lamponi, G. Duan, P. Chanclou, and R. Brenot, Photonics Technology Letters, IEEE 22, 191 (2010).

13. H. Debregeas, C. Ferrari, A. R. Papazian, M. Cappuzzo, F. Klemens, F. Pardo, N. Basavanhally, D. Fleming, M. E. Simon, Y. Low, M. P. Earnshaw, N. Chimot, J. G. Provost, S. Barbet, F. Pommereau, E. Derouin, O. Drisse, F. Lelarge, F. Martin, F. Alexandre, H. Gariah, F. Mallecot, M. Achouche, P. Galli, and L. Fratta, in Semiconductor Laser Conference (ISLC), 2014 International, (2014), pp. 56-57.

14. G. Y. Chu, I. Cano, V. Polo, and J. Prat, Photonics Journal, 8, 3 (2016).

15. G. Y. Chu, A. Lerin, I. Cano, V. Polo, and J. Prat, Chin. Optic Letters, 5, (2016).

16. K. Sato, S. Kuwahara, and Y. Miyamoto, Journal of Lightwave technology 23, 11, 3790 (2005).

17. www.ict-coconut.eu

18. L. Wang, J. An, Y. Wu, J. Zhang, Y. Wang, J. Li, H. Wang, X. Zhang, P. Pan, L. Zhang, Optics Communications, 312, 203 (2014).

19. Q. Feng, W. Li, Y. Wang, Q. Zheng, Z. He, Q. Yang, and S. Yu, Journal of Lightwave Technology, 34, 845 (2016).

20. Govind P. Agrawal, Fiber-Optic Communication Systems, 4th Edition, Wiley, 2010.

21. M. Presi, F. Bottoni, R. Corsini, G. Cossu, E. Ciaramella, IEEE Photon. Technol. Lett., 26, 107, (2014).

22. R. Gaudino, in Proceedings of OFC, OM2A.1, Anaheim, (2013).

23. H. Rohde, E. Gottwald, P. Alves, C. Oliveira, I. Dedic, and T. Drenski, Proc. OFC, OM3H3, Anaheim, 2013. 


\section{REFERENCES}

1. P. Ghelfi, F. Laghezza, F. Scotti, G. Serafino, A. Capria, S. Pinna, D. Onori, C. Porzi, M. Scaffardi, A. Malacarne, V. Vercesi, E. Lazzeri, F. Berizzi, and A. Bogoni, "A fully photonics-based coherent radar system", Nature, 507, 341-345, (2014).

2. J. G. Andrews, S. Buzzi, W. Choi, S. V. Hanly, A. Lozano, A. C. K. Soong, and J. C. Zhang, "What will 5G be," IEEE Journal on Selected Areas in Communications 32, 1065 (2014).

3. S. Smolorz, H. Rohde, E. Gottwald, D. W. Smith, and A. Poustie, "Demonstration of a coherent udwdm-pon with real-time processing," in "Optical Fiber Communication Conference," (Optical Society of America, 2011), p. PDPD4.

4. M. Presi, M. Artiglia, and E. Ciaramella, "Electrical filter-based and low-complexity DPSK coherent optical receiver," Optics letters 39, 6301 (2014).

5. S. A. Gebrewold, L. Marazzi, P. Parolari, R. Brenot, S. P. Duill, R. Bonjour, D. Hillerkuss, C. Hafner, and J. Leuthold, "Reflective-SOA Fiber Cavity Laser as Directly Modulated WDM-PON Colorless Transmitter," IEEE Journal of Selected Topics in Quantum Electronics, 20, 503 (2014).

6. D. Ding, L. Pereira, J. Bauters, M. Heck, G. Welker, A. Vantomme, J. Bowers, D. MJA, and D. Bouwmeester, "Multi-dimensional Purcell effects in an ytterbium-doped ring resonator," Nature Photonics, pp. 1-6 (2016).

7. C. Kazmierski, D. Carrara, K. Lawniczuk, G. Aubin, J.-G. Provost, and R. Guillamet, " $12.5 \mathrm{~Gb}$ operation of a novel monolithic $1.55 \mu \mathrm{m}$ bpsk source based on prefixed optical phase switching," in "Optical Fiber Communication Conference," (Optical Society of America, 2013), pp. OW4J-8.

8. J. Prat, "Technologies for a cost-effective coherent udwdm-pon," in "Optical Fiber Communication Conference," (Optical Society of America, 2015), pp. Th3l-3.

9. G. Y. Chu, I. Cano, V. Polo, C. Kazmierski, R. Brenot, and J. Prat, "Monolithically integrated dual output DEML for full duplex DPSK-ASK and DPSK-SSB ONU in ultra-dense channel spaced access network," Journal of Lightwave technology, 34, 8 (2016).

10. G. Y. Chu, V. Polo, A. Lerín, J. Tabares, I. N. Cano, and J. Prat, "1.25$3.125 \mathrm{~Gb} / \mathrm{s}$ per user PON with RSOA as phase modulator for statistical wavelength ONU," Optics Communications 357, 34 (2015).

11. A. Maho, G. Simon, S. Barbet, F. Lelarge, F. Saliou, P. Chanclou, P. Parolari, L. Marazzi, M. Brunero, M. Martinelli, R. Brenot, "Demystification of the Self-Seeded WDM Access," Journal of Lightwave technology, 34, 2 (2016).
12. G. De Valicourt, D. Make, J. Landreau, M. Lamponi, G. Duan, P. Chanclou, and R. Brenot, "High Gain (30 dB) and High Saturation Power $(11 \mathrm{dBm})$ RSOA Devices as Colorless ONU Sources in Long-Reach HybridWDM/TDM-PON Architecture," Photonics Technology Letters, IEEE 22, 191 (2010)

13. H. Debregeas, C. Ferrari, A. R. Papazian, M. Cappuzzo, F. Klemens, F. Pardo, N. Basavanhally, D. Fleming, M. E. Simon, Y. Low, M. P. Earnshaw, N. Chimot, J. G. Provost, S. Barbet, F. Pommereau, E. Derouin, O. Drisse, F. Lelarge, F. Martin, F. Alexandre, H. Gariah, F. Mallecot, M. Achouche, P. Galli, and L. Fratta, "High-Performance $100 \mathrm{~Gb} / \mathrm{s}$ DWDM Transmitter through Fully Passive Assembly of a Single-Chip Array of Directly Modulated Lasers with a SiO2 AWG," in Semiconductor Laser Conference (ISLC), 2014 International, (2014), pp. 56-57.

14. G. Y. Chu, I. Cano, V. Polo, and J. Prat, "Application on Minimizing Residual AM in DPSK UDWDM-PON ONU by Integrated Dual-EML," Photonics Journal, 8, 3 (2016).

15. G. Y. Chu, A. Lerin, I. Cano, V. Polo, and J. Prat, "Coherent ONU based on $850 \mathrm{~m}$-long cavity-RSOA for next-generation ultra-dense access network," Chin. Optic Letters, 5, (2016).

16. K. Sato, S. Kuwahara, and Y. Miyamoto, "Chirp characteristics of 40$\mathrm{Gb} / \mathrm{s}$ directly Modulated distributed-feedback laser diodes," Journal of Lightwave technology 23,11, 3790 (2005).

17. www.ict-coconut.eu

18. L. Wang, J. An, Y. Wu, J. Zhang, Y. Wang, J. Li, H. Wang, X. Zhang, P. Pan, L. Zhang, "A compact and low-loss $1 \times 8$ optical power splitter using silica-based PLC on quartz substrate," Optics Communications, 312, 203 (2014).

19. Q. Feng, W. Li, Y. Wang, Q. Zheng, Z. He, Q. Yang, and S. Yu, "Colorless Long-reach Duplex WDM-PON with Rayleigh Backscattering Noise Mitigation Using Orthogonal Codes," Journal of Lightwave Technology, 34, 845 (2016).

20. Govind P. Agrawal, Fiber-Optic Communication Systems, 4th Edition, Wiley, 2010.

21. M. Presi, F. Bottoni, R. Corsini, G. Cossu, E. Ciaramella, All DFB-Based Coherent UDWDM PON With $6.25 \mathrm{GHz}$ Spacing and a $>40$ dB Power Budget, IEEE Photon. Technol. Lett., 26, 107, (2014).

22. R. Gaudino, Advantages of Coherent Detection in Reflective PONs, in Proceedings of OFC, OM2A.1, Anaheim, (2013).

23. H. Rohde, E. Gottwald, P. Alves, C. Oliveira, I. Dedic, and T. Drenski, Digital multi-wavelength generation and real time video transmission in a coherent ultra-dense WDM PON, Proc. OFC, OM3H3, Anaheim, 2013. 